\title{
Association of sleep quality with excessive daytime somnolence and quality of life of elderlies of community
}

\author{
Glauber Sá Brandão ${ }^{1,2^{*}}$, Fernanda Warken Rosa Camelier ${ }^{3}$, Antônia Adonis Callou Sampaio², Glaudson Sá Brandão ${ }^{4}$, \\ Anderson Soares Silva ${ }^{5}$, Glaucia Sá Brandão Freitas Gomes ${ }^{2}$, Claudio F. Donner ${ }^{6}$, Luis Vicente Franco Oliveira ${ }^{7}$ \\ and Aquiles Assunção Camelier ${ }^{1,3}$
}

\begin{abstract}
Background: The progressive increase in the elderly population contributes to the fact that studies on human aging have important attention of health professionals and government agents, since they present a great challenge regarding public health. Our objective is to characterize the profile of older people with poor sleep quality and analyze possible associations with excessive daytime somnolence, quality of life and functional mobility.

Methods: This is a cross-sectional descriptive study, involving elderlies of the community, with the questionnaires Pittsburgh Sleep Quality Index (PSQI), Epworth Sleepiness Scale, WHOQOL-OLD and application of the Timed Up and Go test - TUG. Descriptive statistics, Student's t test for paired samples and Pearson's correlation coefficient $(p \leq 0.05)$ were used.

Results: We recruited 131 elderly people, predominantly female (87\%); mean age $68 \pm 7$ years, low per capita income $(84.8 \% \leq 2$ minimum wage), low education ( $86.3 \% \leq 3$ years of study), and mostly staying with relatives (67.9\%), married (39.7\%) or amassed (35.9\%). Seventy-one percent of the sample is above normal weight, $90.1 \%$ of women have an abdominal circumference $\geq 80 \mathrm{~cm}$ and a high prevalence of chronic and psychosocial diseases was identified in the self-report, and the risk of obstructive sleep apnea in 38.2\%. The mean PSQI, Epworth Sleepiness Scale, WHOQOL-OLD and TUG were equal to, respectively, 11.2 $\pm 3.2 ; 8.32 \pm 2.2 ; 84.8 \pm 10.2$ and 8.97 \pm 2 . An association of sleep quality with excessive daytime somnolence and quality of life, while not with functional mobility, was observed.
\end{abstract}

Conclusion: The results of the present study allowed to identify a sleep quality associated with excessive daytime somnolence and quality of life and also to characterize the profile of elders with poor sleep quality.

Keywords: Elderly, Community, Sleep, Quality of life, Excessive daytime somnolence

\section{Background}

The elderly population has the highest growth rate in the world. In socioeconomic developing countries such as Brazil, population aging is a relatively new process and has occurred so rapidly that the more conservative projections indicate that by 2025 it will be the sixth country in the world in terms of the number of elderly people,

\footnotetext{
* Correspondence: gbrandao@uneb.br

'Postgraduate Program in Medicine and Human Health, School of Medicine and Public Health in Bahia, Salvador, BA, Brazil

${ }^{2}$ Department of Education (DEDC-VII), University of the State of Bahia -

UNEB, Rodovia Lomanto Júnior, BR 407, Km127, Senhor do Bonfim, BA CEP 48970-000, Brazil

Full list of author information is available at the end of the article
}

corresponding to $15 \%$ of all the population contingent [1]. This progressive increase in the elderly population contributes to the fact that studies on human aging have important attention of health professionals and government agents, since they present a great challenge regarding public health [2].

The physiological aging is accompanied by alterations in the quality, quantity and architecture of the sleep, being able to lead to diverse diseases, originating considerable social and economic problems [3-6].

Studies using electroencephalography have shown that the cortical status of older people presents a tendency to alertness, associated with a low threshold to wake up in 
response to environmental stimuli and an increased sleep latency. Thus, a reduction in the ability of healthy elderly individuals to initiate and maintain sleep associated with an increase in stages 1 and 2 and a reduction of stage 3 of NREM sleep is observed, as well as a reduction of REM sleep $[4,6]$.

This reduction of slow-wave sleep may be a consequence of the loss of the predominance of parasympathetic activity, as evidenced by the reduction of heart rate variability during sleep in the elderly, and results in a decline in the secretion of human growth hormone, thus reducing restorative capacity $[5,7,8]$.

Among the several diseases that affect the elderly, sleep disorders are among the most prevalent and they are associated with several comorbidities, which consist by a relevant factor of alterations in the perception of general health $[9,10]$. An important epidemiological study with more than 9,000 participants has demonstrated that more than half of the elderly population had at least one complaint of sleep and that the poor quality of sleep would be associated with the presence of biopsychosocial deficiencies such as excessive daytime somnolence, cognitive deficit, depression, fatigue, increased risk of falls, limitations in daily life activities, reduced quality of life and increased incidence of cardiovascular morbidity and mortality [11].

According to the high prevalence of sleep disorders in the geriatric population, we highlight the necessity for information which may subsidize health services in the planning of care in relation to sleep quality and its health impacts in elderly. Therefore, the present study aimed to test the association of sleep quality with excessive daytime somnolence, quality of life and functional mobility of the elderly with poor sleep quality.

\section{Methods}

This is a descriptive, cross-sectional study with a quantitative approach on the profile of the elderly in the community with poor sleep quality, approved by the Research Ethics Committee of the Bahia School of Medicine and Public Health (EBMSP), with CAAE: 39072514.6.0000.5544. All participants in the study signed the Informed Consent Term. The design and conduct of this study followed the guidelines of the Reporting of Observational Studies in Epidemiology (STROBE).

The study was conducted with elderly residents in Senhor do Bonfim-BA, northeast region of Brazil, from July to November 2015. Recruitment occurred throughout the community, through the dissemination of study in local newspapers, radios, religious centers, groups of elderly meeting, senior residence, neighborhood association and in the third age project developed by the city hall, and in the announcement the phone number was provided for interested parties in order to contact the researchers. The inclusion criteria were 60 years old or older and score $\geq 5$ in the Pittsburgh Sleep Quality Index (PSQI) [12]. Participants with a cognitive decline according to the Mental State Mini-Exam [13] and those who were performing some treatment for sleep disorders were excluded from the study.

A questionnaire was applied covering socioeconomic and demographic variables, as well as questions regarding self-reported morbidities and life habits.

Sleep quality was assessed using the Pittsburgh Sleep Quality Index (PSQI) validated for using in Brazil [12]. The PSQI was developed in 1989 and provides a measure of quality of standardized sleep, which discriminates the participants in good or bad sleepers. It consists of seven components, each scored on a scale of zero to three. The components are, respectively; sleep subjective quality; sleep latency; duration of sleep; habitual sleep efficiency; sleep disturbances; using medications for sleep and daytime dysfunction. The scores of the seven components are added together to give an overall score ranging from 0 to 21, with scores of $0-4$ indicating good quality of sleep, 5-10 poor quality and above 10 sleep disorder [14].

Excessive daytime somnolence was assessed using the Epworth Sleepiness Scale (ESS), validated for Brazil. The scale presents eight situations involving activities of daily living in the occurrence of daytime sleepiness. The participants were instructed to rate on a score from 0 to 3 about the probability of feeling slumber or falling asleep in each of the eight specific situations, in which the higher scores indicate a greater chance of sleeping and scores above 10 suggesting a diagnosis of excessive daytime somnolence [15].

To evaluate the potential risk of Obstructive Sleep Apnea (OSA), the Berlin Clinical Questionnaire was used. The instrument includes ten items organized in three categories: snoring and apnea (containing 5 items), daytime somnolence (4 items), systemic arterial hypertension and obesity ( 1 item). The categories 1 and 2 are considered positive if the score of each is greater than or equal to two points, while category 3 is considered positive if the answer to question 10 is YES or if the body mass index (BMI) is greater than $30 \mathrm{~kg} / \mathrm{m}^{2}$. Patients are considered to be at high risk for OSA, when two or more categories present a positive score and, when there is none or only one category with a positive score, the risk for OSA is low [16].

In evaluating the anthropometric variables such as body weight and height, a balance with estadiometer was used (mechanical anthropometric scale, $150 \mathrm{~kg}$ - Welmy', Sao Paulo, Brazil) properly calibrated; to measure the waist circumference, a tape measure was used and the Body Mass Index (BMI) was calculated from the weight in kilograms divided by the height in meters squared.

The level of physical activity was evaluated through the International Questionnaire of Physical Activity (IPAQ) 
adapted for the elderly [17]. It is an instrument which allows estimating the weekly energy expenditure of physical activities related to work, transportation, domestic tasks and leisure, carried out continuously for at least $10 \mathrm{~min}$ with moderate and/or vigorous intensity during a normal/ usual week. For the present study, the last variable was dichotomized, and it was considered inactive that participant who executed less than 150 min per week of moderate and/or vigorous and active that participant who executed physical activities for more than 150 min per week.

Functional mobility was assessed using the Timed $U p$ and Go test (TUG), a simple test which evaluates the execution speed in getting up from a chair with arms, to walk three meters forward, to turn around, to walk back and to sit on the chair again. The execution time less than $10 \mathrm{~s}$ suggests totally free and independent individual; those who perform the test between 10 and $19 \mathrm{~s}$ are considered independent, from 20 to $29 \mathrm{~s}$ those who are in a so-called "gray zone", which is, they demonstrate difficulties for tasks of daily living and limited functional capacity. Those who present a time score of 30 or more seconds tend to be totally dependent on many basic and instrumental activities of daily living [18].

To evaluate the quality of life used the WHOQOL-OLD containing six facets each of 4 items, which was evaluated by Likert scale (1 to 5 points): Facet I - "Sensory Operation"; Facet II - "Autonomy"; Facet III - " Past, Present and Future Activities"; Facet IV - "Social Participation"; Facet V "Death and Dying"; Facet VI - "Intimacy". Each of the facets has 4 items, thus for all facets the score of the possible values may range from 4 to 20 , and the scores of these six facets or the values of the 24 items may be combined to produce a "global" score of the quality of life in the elderly and the higher the score the better the quality of life [19].

The data were tested for normality (Kolmogorov-Smirnov test) were subjected to a descriptive analysis by the absolute frequencies and percentages for categorical variables and measures of central tendency and dispersion for numerical variables. It was used the Student's T test for comparison of means, and the graphical representation of the box diagram (boxplot) to demonstrate the behavior of continuous variables between groups. The Pearson correlation coefficient (r) was also used to analyze the association of PSQI with the following variables: ESE, TUG and WHOQOL-OLD. For decision criteria, it was adopted the significance level of $5 \%(p \leq 0.05)$ and statistical procedures were processed and analyzed in Statistical Package of the Social Sciences (SPSS) for Windows', version 21.

\section{Results}

One hundred and ninety-one potential participants were recruited from the community. Twenty-eight refused to participate in the study and 32 were excluded according to the eligibility criteria, which left only 131 participants, which represented $80.4 \%$ of the sample. A summary of participants' flow over the course of the study is presented in Fig. 1.

Table 1 shows the predominance of females (87\%); with a mean age of $68 \pm 7$ years, the majority being between 60 and 69 years of age. This is a population predominantly low income per capita ( $84.8 \% \leq 2$ minimum wage), low education $(86.3 \% \leq 3$ years of study) and, mostly living with relatives $(67.9 \%)$, married $(39.7 \%)$ or cohabiting (35.9\%). Regarding anthropometry, $47.3 \%$ of the elderly were overweight and $23.7 \%$ were obese, which is associated with the fact that $90.1 \%$ of the women had abdominal circumference $\geq 80 \mathrm{~cm}$.

Among the self-reported morbidities, anxiety (58\%), arthrosis (37.4\%), systemic arterial hypertension (33.6\%), diabetes (26\%) and chronic pain were the most prevalent (38.9\%). Regarding lifestyle habits, $90.1 \%$ of the elderly reported not smoking, and out of these non-smokers, $12.2 \%$ reported smoking in the past. Most participants did not report alcohol consumption and presented a level of physical activity considered active (>150 min/ week), according to the IPAQ (Table 2).

Data regarding sleep quality, daytime somnolence symptoms, quality of life and functional mobility (TUG) are described in Table 3.

From the 131 elderlies with poor sleep quality, 76 (58\%) had sleep disorder (PSQI score > 10 points), 40 (30.5\%) had excessive daytime somnolence assessed by ESS, and $50(38.2 \%)$ were considered to be at high risk for OSA because they presented positive scores in two or more categories of the Berlin Clinical Questionnaire. The average nightly sleep time was $5.7 \pm 0.94 \mathrm{~h}$ and 55 elderlies (42\%) reported waking up at night to go to the bathroom. In Table 4 we can see the comparison of baseline characteristics by Pittsburgh Sleep Quality Index.

Table 5 and Table 6 show the comparison of the questionnaire scores according to the gender and BMI of the subjects involved in this study.

After dividing the sample into two groups with different PSQI scores (5 to 10 versus $>10$ points) and performing Student's t-test to compare ESS means between groups $(p<0.01)$, it was represented, in the Fig. 2, the ESS score distribution for each group using the boxplot graph, with a median 7 (4-13) for the group (5 to 10), median 9 (4-14) the group (>10). The correlation of the PSQI score with ESS was moderate and statistically significant $(r=0.4$ and $<0.001)$.

By using the same groups of the PSQI (5 to 10 versus $>10$ points), and after carrying out the Student's t test to compare the WHOQOL-OLD means between the groups $(\mathrm{p}<0.01)$, it was represented in Fig. 3 , the WHOQOL-OLD score for each group, with a median of 85 (63-111) for the subgroup (5 to 10) and a median of $84(62-104)$ for the subgroup (>10). An association 


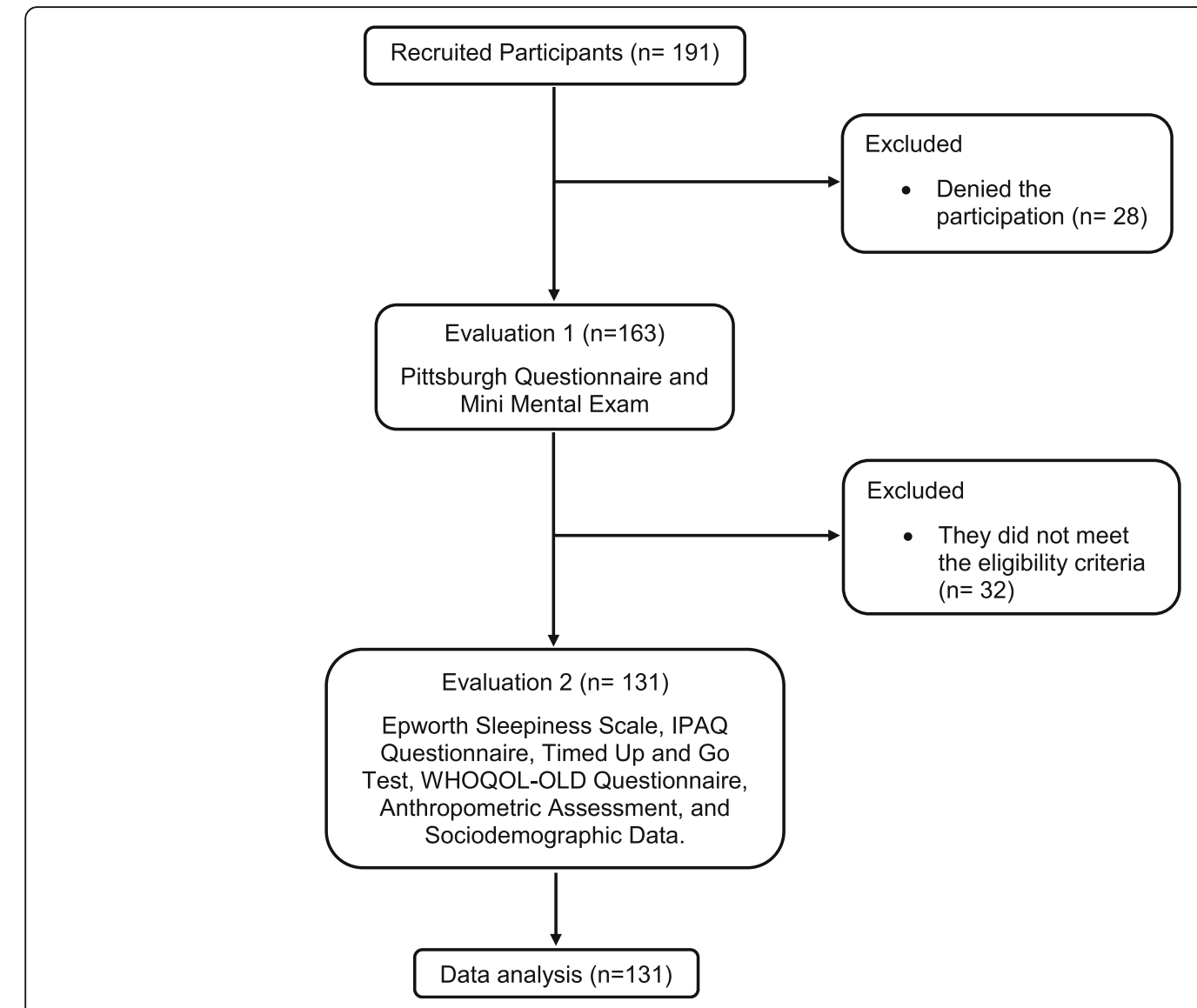

Fig. 1 Flowchart of the study

between PSQI and WHOQOL-OLD scores $(r=-0.285$ and $\mathrm{p}<0.01)$ was identified.

Regarding the TUG, the PSQI group (5 to 10) had a median 8.5 (5-14) and the group with PSQI $(>10)$ had a median 8.9 (5.7-14), no difference between groups and a weak association were found, with no statistical significance between TUG and IPAQ $(r=-0.13$ and $p=0.89)$.

\section{Discussion}

In the sample of patients in the present study, we observed the predominance of female gender (87\%), reflecting the greater longevity of women in history and worldwide. The great number of females in old age is associated with several aspects, such as less exposure to occupational risk factors, lower prevalence of smoking and alcoholism, greater attention to health and self-care, and greater frequency of using the health services [20, 21].

There was a preponderance of 60 to 69 years of age (51.9\%), with a mean age $68 \pm 7$ years, converging with international [22] and national studies [23], positively qualifying the external validity of the present study. This preeminence of age at the lower limit is evidence of the recent aging of the Brazilian population, unlike the developed countries, where the elderly is aged 80 and over [24].
In the present study, $75.6 \%$ of the elderly have low educational level, reflecting the intense socioeconomic inequality experienced in the country $[25,26]$. In addition, a low economic status was identified, with $44.3 \%$ presenting a family income below 1 minimum wage, converging with epidemiological profile studies conducted in Brazilian cities [26]. Despite these socioeconomic and demographic characteristics, it was possible to properly apply the questionnaires and extract important information by analyzing the results, encouraging further studies.

In the anthropometric analysis, the BMI indicates that $47.3 \%$ are overweight and $23.7 \%$ are obese, which is, $71 \%$ of the interviewed elderly are overweight considered adequate [27]. These weight changes associated with the fact that $90.1 \%$ of the women present waist circumference $\geq 80 \mathrm{~cm}$, present a high risk of cardiovascular diseases [28] and the Obstructive Sleep Apnea Syndrome, possibly related to pharyngeal narrowing by fat deposition in its walls or the parapharyngeal structures [29]. On the other hand, growing evidence indicates that short sleep duration, as presented in the present study, avoiding a possible selection bias, the PSQI, ESS, WHOQOL-old, Berlin Questionnaire and IPAQ questionnaire scores were compared according to the gender and also according to 
Table 1 Sociodemographic and anthropometric characteristics of the interviewed elderly

\begin{tabular}{|c|c|c|}
\hline \multirow[b]{2}{*}{ Variables } & \multicolumn{2}{|c|}{ Total $(n=131)$} \\
\hline & $\mathrm{N}$ & $\%$ \\
\hline \multicolumn{3}{|l|}{ Gender } \\
\hline Female & 114 & 87 \\
\hline Male & 17 & 13 \\
\hline \multicolumn{3}{|l|}{ Age (years) } \\
\hline 60 to 69 & 68 & 51.9 \\
\hline 70 to 70 & 48 & 36.6 \\
\hline$\geq 80$ & 15 & 11.5 \\
\hline \multicolumn{3}{|l|}{ Education } \\
\hline Illiterate & 14 & 10.7 \\
\hline 1 to 3 years & 99 & 75.6 \\
\hline 4 to 7 years & 15 & 10.7 \\
\hline 8 years or more & 3 & 2.3 \\
\hline \multicolumn{3}{|l|}{ Monthly income per capita } \\
\hline$<1 \mathrm{MW}$ & 58 & 44.3 \\
\hline 1 to $2 \mathrm{MW}$ & 53 & 40.5 \\
\hline$>2$ to $3 \mathrm{MW}$ & 12 & 9.2 \\
\hline$>3 \mathrm{MW}$ & 8 & 6.1 \\
\hline \multicolumn{3}{|l|}{ Family composition } \\
\hline Live alone & 42 & 32.1 \\
\hline Live with relatives & 89 & 67.9 \\
\hline \multicolumn{3}{|l|}{ Marital status } \\
\hline Single & 11 & 8.4 \\
\hline Married & 52 & 39.7 \\
\hline Widowed & 8 & 6.1 \\
\hline Cohabiting & 47 & 35.9 \\
\hline Divorced & 13 & 9.9 \\
\hline \multicolumn{3}{|l|}{$\mathrm{BMI}\left(\mathrm{Kg} / \mathrm{m}^{2}\right)$} \\
\hline Low weight $(<18.5)$ & 4 & 3.1 \\
\hline Normal (18.5 to 24.9 ) & 34 & 26.0 \\
\hline Overweight (25.0 to 29.9) & 62 & 47.3 \\
\hline Obese $(\geq 30)$ & 31 & 23.7 \\
\hline \multicolumn{3}{|l|}{ Waist Circumference (cm) } \\
\hline \multicolumn{3}{|l|}{ Women } \\
\hline Increased risk $(\mathrm{WC} \geq 80 \mathrm{~cm})$ & 118 & 90.1 \\
\hline \multicolumn{3}{|l|}{ Men } \\
\hline Increased risk ${ }^{a}(W C \geq 94 \mathrm{~cm})$ & 2 & 1.5 \\
\hline
\end{tabular}

$M W$ minimum wage during the study (in real) $=\mathrm{R} \$ 788.00, B M I$ Body mass index, WC Waist Circumference

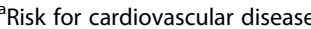

the BMI of the subjects involved in the study. No significant difference was observed.

Where the average nightly sleep time was $5.7 \pm 0.94 \mathrm{~h}$, it is considered a risk factor for the development of obesity
Table 2 Self-reported morbidities, life habits and physical activity level of the interviewed elderly

\begin{tabular}{|c|c|c|}
\hline \multirow[b]{2}{*}{ Variables } & \multicolumn{2}{|c|}{ Total $(n=131)$} \\
\hline & $\mathrm{N}$ & $\%$ \\
\hline \multicolumn{3}{|l|}{ Morbidities } \\
\hline Diabetes & 34 & 26.0 \\
\hline Systemic arterial hypertension & 44 & 33.6 \\
\hline Urinary incontinence & 32 & 24.4 \\
\hline Stroke & 6 & 4.6 \\
\hline Respiratory disease & 14 & 10.7 \\
\hline Arthritis & 24 & 18.3 \\
\hline Arthrosis & 49 & 37.4 \\
\hline Fibromyalgia & 6 & 4.6 \\
\hline Depression & 29 & 22.1 \\
\hline Anxiety & 77 & 58.8 \\
\hline Chronic pain & 51 & 38.9 \\
\hline \multicolumn{3}{|l|}{ Smoking } \\
\hline Yes & 13 & 9.9 \\
\hline No & 118 & 90.1 \\
\hline Ex-smokers & 14 & 12.2 \\
\hline \multicolumn{3}{|l|}{ Alcohol use } \\
\hline Yes & 17 & 13.0 \\
\hline No & 114 & 87.0 \\
\hline \multicolumn{3}{|l|}{ Physical Activity Level - IPAQ } \\
\hline Inactive (< $150 \mathrm{~min} /$ week) & 17 & 13 \\
\hline Active (> 150 min/week) & 114 & 87 \\
\hline
\end{tabular}

and its subsequent complications [30, 31]. Sleep loss may lead to metabolic and endocrine disorders, including reduced glucose tolerance and changes in appetiteregulating hormones, such as the ghrelin, a hunger-promoting hormone which increases with sleep restriction, while leptin is the hormone which contributes to satiety is reduced [29, 30].

Associated with the growing process of population aging, functional changes occur which are characteristic of this age group, predisposing to the appearance of pathologies classified as chronic non-transmissible [32]. The present study found a high frequency of elderly patients with self-reported chronic and psychosocial disorders,

Table 3 Mean values and standard deviation for the PSQI, ESE, WHOQOL-OLD, and TUG performance time in the elderly community $(n=131)$

\begin{tabular}{lll}
\hline Variables & Mean \pm SD & Variation \\
\hline Sleep Quality (PSQI) & $11.2 \pm 5.6$ & $5-18$ \\
Excessive daytime somnolence (ESS) & $8.3 \pm 2.2$ & $4-14$ \\
Quality of life (WHOQOL-OLD) & $84.8 \pm 10$ & $62-111$ \\
Functional mobility (TUG) & $9.0 \pm 2.0$ & $5-14$ \\
\hline
\end{tabular}


Table 4 Comparison of baseline characteristics by Pittsburgh Sleep Quality Index

\begin{tabular}{llll}
\hline Variables & 5 a 10 & $>10$ & $p$ \\
\hline Gender (\% women) & 50 & 64 & 0.26 \\
Age (years) & $71.2 \pm 6.2$ & $69.8 \pm 7.5$ & 0.07 \\
BMI (Kg/m ${ }^{2}$ ) & $27.3 \pm 4.2$ & $27.2 \pm 4.1$ & 0.95 \\
Waist Circumference (cm) & $92.8 \pm 10.6$ & $92.4 \pm 10.3$ & 0.82 \\
Self-reported morbidities ( $\mathrm{n})$ & $1.73 \pm 1.2$ & $1.82 \pm 1.7$ & 0.74 \\
Per capita income & 43 & 55 & 0.95 \\
(\% $\leq 2$ minimum wages) & & & \\
Education (\% $\leq 3$ years of study) & 45 & 62 & 0.28 \\
Housing (\% live with relatives) & 42 & 47 & 0.08 \\
\hline
\end{tabular}

highlighting the anxiety, followed by chronic pain, osteoarthritis, hypertension, and diabetes, as observed in epidemiological studies on aging [33, 34]. The chronic and psychosocial diseases are negatively associated with selfperception of health, quality of life and sleep quality of the elderly [32]. This panorama points to the real necessity to strengthen the health promotion actions.

Regarding lifestyle habits, few elderly people reported smoking and alcohol consumption, which may be explained by the predominance of females in the sample, considering that women devote more attention to health and self-care $[20,21]$. According to the IPAQ, most of participants were considered active, diverging from other studies in which the level of physical activity is presented inversely proportional to income and education [33, 34].

In evaluating the quality of nocturnal sleep, the sample showed an overall average score $11.2 \pm 5.6$ in the PSQI, classified as sleep disorder. This result is similar to that presented by other studies $[35,36]$. Among the problems related to nocturnal sleep, we highlight the high risk of OSA in $38.2 \%$ of the sample, corroborating the important epidemiological study where it was found that the incidence of OSA is proportional to age, female gender and low socioeconomic class and presents important interference in sleep quality [37]. It is worth noting the necessity to wake up to go to the bathroom, reported by $42 \%$, which may also interfere with sleep quality [38].

Table 5 Comparison of the questionnaires scores according to gender

\begin{tabular}{llll}
\hline Variables & Female & Male & $p$ \\
\hline PSQI & $11.2 \pm 3.3$ & $11.6 \pm 2.5$ & 0.6 \\
ESS & $8.3 \pm 2.2$ & $8.2 \pm 1.9$ & 0.8 \\
WHOQOL-old & $84.4 \pm 10.4$ & $83.9 \pm 10.6$ & 0.8 \\
BQ (\% high risk) & 38 & 34 & 0.2 \\
IPAQ (\% actives) & 85 & 90 & 0.1 \\
\hline
\end{tabular}

PSQI Pittsburgh Sleep Quality Index, ESS Epworth Sleepiness Scale, BQ Berlin Questionnaire, IPAQ International Physical Activity Questionnaire
Table 6 Comparison of the questionnaire scores according to Body Mass Index

\begin{tabular}{lllll}
\hline Questionnaires & Normal weight & Overweight & Obese & $p$ \\
\hline PSQI & $11.21 \pm 3.7$ & $11.18 \pm 3$ & $11.34 \pm 3$ & 0.97 \\
ESS & $7.94 \pm 2.4$ & $8.37 \pm 2.2$ & $8.66 \pm 2.1$ & 0.43 \\
BQ (\% high risk) & 37 & 36 & 38 & 0.13 \\
IPAQ (\% actives) & 89 & 87 & 86 & 0.24 \\
\hline
\end{tabular}

PSQI Pittsburgh Sleep Quality Index, ESS Epworth Sleepiness Scale, BQ Berlin Questionnaire, IPAQ International Physical Activity Questionnaire

As for excessive daytime sleepiness, 40 elderly participants $(30.5 \%)$ had a score $\geq 10$ in ESS, however the mean score of the sample was $8.32 \pm 2.2$, which is not indicative of excessive daytime somnolence, converging with previous studies [36, 39]. Excessive diurnal somnolence reverberates in the life of the elderly predisposing to naps that, when prolonged, may be harmful because they interfere in the duration and quality of nocturnal sleep [38]. In the present study, the daytime somnolence is directly associated with worse perception of nocturnal sleep quality, corroborating previous investigations $[40,41]$. The nocturnal sleep restriction, identified in our sample through PSQI (nocturnal sleep duration $5.7 \pm 0.94$ ), may result in a sensation of physical and mental fatigue during the day, predisposing to excessive daytime sleepiness [42].

The quality of life of the interviewed elderly was considered good, with a mean score in the WHOQOL-OLD 84.8 \pm 10 , similar to that found in another study which has compared the quality of life among the young and very old elders and obtained a total score $84.1 \pm 11.5$ and $83.3 \pm$ 12.3 , considered as good quality of life for both groups [43]. In the present study, it was found that the deterioration of sleep quality presents a significant but weak association, with the deterioration in the perception of quality of life, in consonance with results presented in other studies [44].

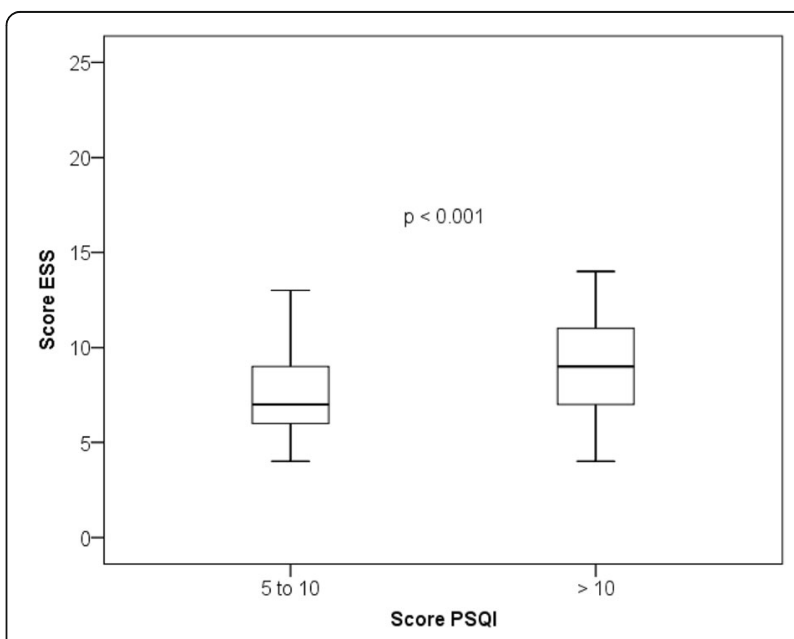

Fig. 2 Distribution boxplot graph ESS score of the two groups with different scores in PSQI 


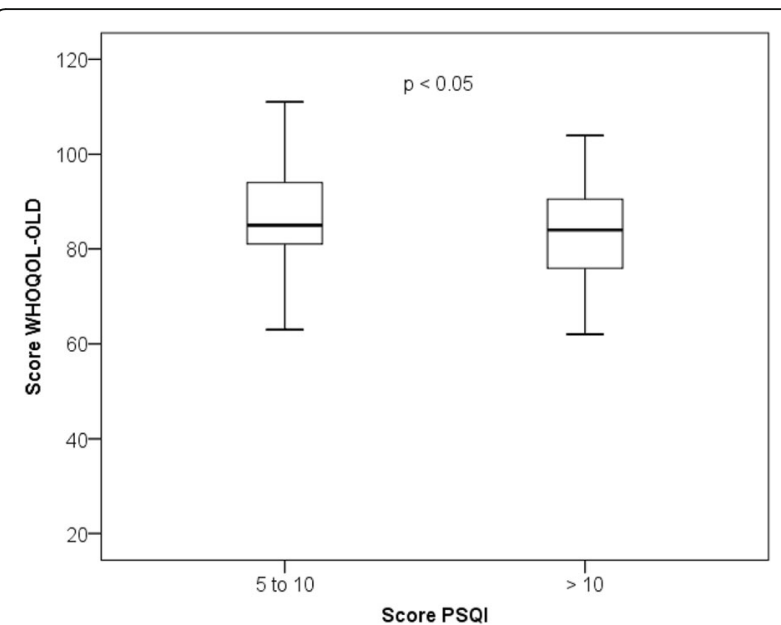

Fig. 3 Distribution boxplot graph of WHOQOL-OLD score in relation to two subgroups with different scores in PSQI

Sleep deprivation may adversely affect the quality of life of elderly by altering proprioception, neuromuscular reaction time and postural control, reducing independence and autonomy [45]; increasing pain sensitivity [46]; triggering neurobehavioral impairments such as decline in attention and memory and it may be a risk factor for the development of stress, anxiety and depression [47].

To move from sitting to standing position is an activity considered to be complex and most performed in the daily life of the elderly, and it is important in the evaluation of functional decline, which occurs proportionally as the age advances [48]. Functional mobility was assessed through the TUG and obtained a mean score $8.9 \pm 2$, suggestive of totally unrestricted, independent elderly and classified as low risk for falls [18]. According to the results presented, it is possible to hypothesize that sleep disturbance is not associated with changes in functional mobility and risk of falls in the elderly, diverging from previous studies that obtained this association [49], however, we cannot exclude the possibility of type II statistical error. These aspects may be evaluated in future studies specially designed for this purpose.

The study presents some limitations that must be considered. The cross-sectional design shows the reverse causality bias, since it is not possible to obtain information regarding the natural history of the diseases and/or events; the study recruitment was directed at older adults in the general community who presented self-reported sleep complaints but the results may be more clinically significant if the recruitment is performed in the elderly with clinical diagnosis of sleep disturbance through polysomnography or polygraphy; The questionnaires were used in the elderly in different degrees of education, which may interfere in the quality of the answers, but all the subjects who presented difficulties in answering the questionnaires were assisted; only the elderly with a PSQI score $\geq 5$ were studied, and the elderly with good sleep quality were not studied.

\section{Conclusion}

Among the elderly in the community selected with PSQI scores $\geq 5$, the poor quality of nocturnal sleep is associated with worse quality of life and the presence of symptoms of excessive daytime somnolence, however not significantly influencing functional mobility.

\section{Abbreviations}

BMI: Body mass index; ESS: Epworth Sleepiness Scale; IPAQ: International Questionnaire of Physical Activity; OSA: Obstructive Sleep Apnea;

PSQI: Pittsburgh Sleep Quality Index; STROBE: Reporting of Observational Studies in Epidemiology; TUG: Timed Up and Go test; WHOQOL-OLD: World Health Organization Quality of Life for Older Adults

\section{Acknowledgments}

The authors thank the elderly who agreed to participate in the study; the Bahia State University - UNEB by funding through the Program to Support Training of Teachers and Administrative Technicians (PAC) and the members of the QUALES research group for the dedication in data collection.

Funding

This study was funded by the State University of Bahia, through the Support Program for the Training of Teachers and Administrative Technicians (PAC) without influencing any of the stages of the study, from the conception, development, analysis and interpretation of the results.

LVFO received grants Research Productivity, modality PQIB; Process no.

313053 / 2014-6 of National Council for Scientific and Technological

Development (local acronym CNPq), Brazil.

Availability of data and materials

All data and materials are available upon request.

\section{Authors' contributions}

GSB', LVFO, and AAC provided the concept of the study, created the hypothesis, and wrote the original proposal. GSB', ASS, GSBFG, AACS and FWRC obtained ethics approval. GSB ${ }^{1}, A A C S, G S B F G$ and $G^{4} B^{4}$ will be participated in the data collection and performed clinical evaluations. GSB', LVFO, and AAC prepared the drafted manuscript. GSB ${ }^{4}$, LVFO, FWRC, CFD and $G S B^{1}$ were involved in the critical revision of the manuscript. GSB', AAC and LVFO co- lead investigators. GSB' ${ }^{1}$ AAC, and LVFO wrote this protocol paper, with input from all co-authors. All authors read and approved the final manuscript.

\section{Ethics approval and consent to participate}

The study was approved by the Research Ethics Committee of the Bahia School of Medicine and Public Health, process 39,072,514.6.0000.5544. All participants signed an informed consent form. The results of this protocol study will be published in peer-reviewed journals as well as national and international conferences. The data collected will also be made available according demand.

\section{Consent for publication}

All patients give their consent for publication in the consent form. However, every attempt will be made to ensure the patients' anonymity.

\section{Competing interests}

The authors declare that they have no competing interests.

\section{Publisher's Note}

Springer Nature remains neutral with regard to jurisdictional claims in published maps and institutional affiliations.

\section{Author details}

${ }^{1}$ Postgraduate Program in Medicine and Human Health, School of Medicine and Public Health in Bahia, Salvador, BA, Brazil. ${ }^{2}$ Department of Education (DEDC-VII), University of the State of Bahia - UNEB, Rodovia Lomanto Júnior, 
BR 407, Km127, Senhor do Bonfim, BA CEP 48970-000, Brazil. ${ }^{3}$ Department of Life Sciences (DCV), University of the State of Bahia - UNEB, Salvador, BA, Brazil. ${ }^{4}$ Diagnostic and specialty clinic (IMAIS), Senhor do Bonfim, BA, Brazil. ${ }^{5}$ Sleep Laboratory, Rehabilitation Sciences Master's and PhD Degree Program, Nove de Julho University (UNINOVE), Sao Paulo, SP, Brazil. ' Mondo Medico, Multidisciplinary \& Rehabilitation Outpatient Clinic, Borgomanero, NO, Italy. ${ }^{7}$ Medical School , University Center of Anapolis - UniEVANGELICA, Anapolis, $\mathrm{GO}$, Brazil.

\section{Received: 7 September 2017 Accepted: 25 February 2018} Published online: 15 March 2018

\section{References}

1. Instituto Brasileiro de Geografia e Estatística - IBGE. Dados do Censo. Diário Oficial da República Federativa do Brasil. Brasília: DF; 2010. p. 2010

2. Ministério da Saúde; Secretaria de Atenção à Saúde; Departamento de Atenção Básica. Envelhecimento e saúde da pessoa idosa. Brasília; 2006 Caderno de Atenção Básica, n. 19

3. Ancoli-Israel S. Sleep and its disorders in aging populations. Sleep Med. 2009;10(1):7-11.

4. Bruce EN, Bruce MC, Vennelaganti S. Sample entropy tracks changes in EEG power Spectrum with sleep state and aging. J Clin Neurophysiol. 2009;26(4):257-66

5. Brandenberger G, Viola AU, Ehrhart J, Charloux A, Geny B, Piquard F, et al. Age-related changes in cardiac autonomic control during sleep. J Sleep Res. 2003;12(3):173-80

6. Landolt HP, Borbély AA. Age-dependent changes in sleep EEG topography. Clin Neurophysiol. 2001;112(2):369-77.

7. Vitiello MV, Larsen LH, Moe KE. Age-related sleep change: gender and estrogen effects on the subjective-objective sleep quality relationships of healthy, noncomplaining older men and women. J Psychosom Res. 2004;56(5):503-10.

8. Dijk DJ, Duffy JF, Riel E, Shanahan TL, Czeisler CA. Ageing and the circadian and homeostatic regulation of human sleep during forced desynchrony of rest, melatonin and temperature rhythms. J Physiol. 1999;15(2):611-27.

9. Fragoso CAV, Gill T. Sleep complaints in community-living older persons: a multifactorial geriatric syndrome. J Am Geriatr Soc. 2009;55(11):1853-66.

10. Durcan L, Wilson F, Cunnane G. The effect of exercise on sleep and fatigue in rheumatoid arthritis: a randomized controlled study. J Rheumatol. 2014. 41(10):1966-73.

11. Foley DJ, Monjan AA, Brown SL, Simonsick EM, Wallace RB, Blazer DG. Sleep complaints among elderly persons: an epidemiologic study of three communities. Sleep. 1995;18(6):425-32.

12. Bertolazi AN, Fagondes SC, Hoff LS, Dartora EG, Silva MIC, Barba MEF, et al. Validation of the Brazilian Portuguese version of the Pittsburgh sleep quality index. Sleep Med. 2011;12(1):70-5.

13. Brucki SMD, Nitrin R, Caramelli P, Bertolucci PHF, Okamoto $\Vdash H$. Sugestões para o uso do mini-exame do estado mental no Brasil. Arq Neuropsiquiatr. 2003;61(3 B):777-81.

14. Buysse DJ, Reynolds CF, Monk TH, Berman SR, Kupfer DJ. The Pittsburgh sleep quality index: a new instrument for psychiatric practice and research. Psychiatry Res. 1989;28(2):193-213.

15. Bertolazi AN, Fagondes SC, Hoff LS, Pedro VD, Barreto SSM, Johns MW, et al. Portuguese-language version of the Epworth sleepiness scale: validation for use in Brazil. J Bras Pneumol. 2009;35(9):877-83.

16. Netzer NC, Stoohs RA, Netzer CM, Clark K, Strohl KP. Using the Berlin questionnaire to identify patients at risk for the sleep apnea syndrome. Ann Intern Med. 1999;131:485-91.

17. Mazo GZ, Benedetti TB. Adaptation of the international physical activity questionarie for the elderly. Rev Bras Cineantropometria e Desempenho Hum. 2010;12(6):480-4.

18. Podsiadlo D, Richardson S. The timed "up \&amp; go": a test of basic functional mobility for frail elderly persons. J Am Geriatr Soc. 1991;39(2):142-8.

19. Fleck MP, Chachamovich E, Trentini CM. WHOQOL-OLD Project: method and focus group results in Brazil. Rev Saude Publica. 2003;37(6):793-9.

20. Austad SN, Bartke A. Sex differences in longevity and in responses to antiaging interventions: a mini-review. Gerontology. 2015;62(1):40-6.

21. Luy MGK. Do women live longer or that men die earlier? Reflections on the causes of sex differences in life expectancy. Gerontology. 2014;60:143-53.

22. Martinez BF, Flores MEP, Forjaz MJ, Mayoralas GF, Pérez FR, Martin PM. Self-perceived health status in older adults : regional and sociodemographic inequalities in Spain Estado de saúde percebido em idosos: desigualdades regionais e sociodemográfi cas na Espanha. Rev Saúde Pública. 2012;46(2):310-9.

23. Regina $M$, Alvarenga $M$, Accioly $M$, Domingues $R$, Amendola F, Faccenda $O$. Rede de suporte social do idoso atendido por equipes de Saúde da Família. Cien Saude Colet. 2011;16(5):2603-11.

24. Sousa Al, Lynn DS. Perfil sociodemográfico e estado de saúde auto-referido entre idosas de uma localidade de baixa renda. Esc Anna Nery. Rev Enferm. 2008;12(4):706-16

25. Borges PLC, Bretas RP, Azevedo SF, Barbosa JMM. Perfil dos idosos frequentadores de grupos de convivência em Belo Horizonte, Minas Gerais. Brasil Cad Saúde Pública. 2008;24(12):2798-808.

26. Louvison MCP, Lebrão ML, Duarte YAO, Laurenti R. Desigualdades nas condições de saúde e no uso de serviços entre as pessoas idosas do município de São Paulo: uma análise de gênero e renda. Saúde Coletiva. 2008;5(24):189-94

27. Associação Brasileira para o Estudo da Obesidade e da Síndrome Metabólica Diretrizes Brasileiras de Obesidade 2009/2010 / ABESO Associação Brasileira para o Estudo da Obesidade e da Síndrome Metabólica. - 3.ed. - Itapevi, SP : AC Farmacêutica; 2009.

28. Cercato C, Mancini MC, Maria A, Arguello C, Passos Q, Mara S, et al. Systemic hypertension, diabetes mellitus, and dyslipidemia in relation to body mass index: evaluation of a brazilian population. Rev Hosp Clin Fac Med S Paulo. 2004:59(3):113-8.

29. Pannain S, Miller A, Cauter VE. Sleep loss, obesity and diabetes: prevalence, association and emerging evidence for causation. Obes Metab-Milan. 2008;4(1):28-41.

30. Morselli L, Leproult R, Balbo M, Spiegel K. Role of sleep duration in the regulation of glucose metabolism and appetite. Best pr res. Clin Endocrinol Metab. 2010:24(5):687-702

31. Knutson KL. Sleep duration and cardiometabolic risk: a review of the epidemiologic evidence. Best pr res. Clin Endocrinol Metab. 2010;24:731-43.

32. Veras RP. Estratégias para o enfrentamento das doenças crônicas: um modelo em que todos ganham. Rev Bras Geriatr e Gerontol. 2011;14(4):779-86.

33. Clares JWB, Freitas MC, Almeida PC, Galiza FT, Queiroz TA. Perfil de idosos cadastrados numa unidade básica de saúde da família de Fortaleza-CE. Rev RENE. 2011;12:988-94.

34. Feliciano AB, Moraes AS, Freitas ICM. O perfil do idoso de baixa renda no Município de São Carlos, São Paulo, Brasil : um estudo epidemiológico. Cad Saúde Pública. 2004;20(6):1575-85.

35. Chen M-C, Liu H-E, Huang H-Y, Chiou A-F. The effect of a simple traditional exercise programme (Baduanjin exercise) on sleep quality of older adults: a randomized controlled trial. Int J Nurs Stud. 2012;49(3):265-73.

36. Li F, Fisher KJ, Harmer P, Irbe D, Tearse RG, Weimer CJ. Tai chi and self-rated quality of sleep and daytime sleepiness in older adults: a randomized controlled trial. Am Geriatr Soc. 2004;52(6):892-900.

37. Tufik S, Santos-Silva R, Taddei JA, Bittencourt LR. Obstructive sleep apnea syndrome in the Sao Paulo epidemiologic sleep study. Sleep Med. 2010 May;11(5):441-6.

38. Asplund R. Nocturia: consequences for sleep and daytime activities and associated risks. Eur Urol Suppl. 2005;3(6):24-32.

39. Martin IL, Ancoli-lsrael S. Napping in older adults. Sleep Med Clin. 2006;1(2):177-86.

40. Carskadon MA, Brown ED, Dement WC. Sleep fragmentation in the elderly: relation with the tendency to daytime sleep. Neurobiol Envelhec. 1982;3(4):321-7.

41. Goldman SE, Hall M, Boudreau R, Matthews KA, Cauley JA, Ancoli-Israel S, et al. Association between nighttime sleep and napping in older adults. Sleep. 2008;31(5):733-40.

42. Ancoli-Israel S, Ayalon L, Salzman C. Sleep in the elderly: normal variations and common sleep disorders. Harv Rev Psychiatry. 2008;16(5):279-86.

43. Maués $C R$, Paschoal SMP, Jaluul O, França CC, Jacob Filho W. Avaliação da qualidade de vida : comparação entre idosos jovens e muito idosos. Rev Bras Clin Med. 2010;8(5):405-10.

44. Lo CMH, Lee PH. Prevalence and impacts of poor sleep on quality of life and associated factors of good sleepers in a sample of older Chinese adults. Health Qual Life Outcomes. 2012;10(1):72.

45. Dattilo M, Antunes HKM, Medeiros A, Mônico Neto M, Souza HS, Tufik S, et al. Sleep and muscle recovery: Endocrinological and molecular basis for a new and promising hypothesis. Med Hypotheses. 2011;77(2):220-2.

46. Haack M, Sanchez E, Mullington JM. Elevated inflammatory markers in response to prolonged sleep restriction are associated with increased pain experience in healthy volunteers. Sleep. 2007;30(9):1145-52. 
47. Spiegelhalder K, Regen W, Nanovska S, Baglioni C, Riemann D. Comorbid sleep disorders in neuropsychiatric disorders across the life cycle. Curr Psychiatry Rep. 2013;15(6):364.

48. Valduga $\mathrm{R}$, Lopes BS, Farias DL, Nascimento Dda C, DCL V, Valduga LV, et al. Risk of falls and the relationship with the functionality and fear of falling in the older women. Rev Bras Ciência e Mov. 2016;24(1):153-66.

49. Brassington GS, King AC, Bliwise DL. Sleep problems as a risk factor for falls in a sample of adults aged 64 to 99 years living in the community. J Am Geriatr Soc. 2000;48(10):1234-40.

Submit your next manuscript to BioMed Central and we will help you at every step:

- We accept pre-submission inquiries

- Our selector tool helps you to find the most relevant journal

- We provide round the clock customer support

- Convenient online submission

- Thorough peer review

- Inclusion in PubMed and all major indexing services

- Maximum visibility for your research

Submit your manuscript at www.biomedcentral.com/submit
Biomed Central 